\title{
LA IDEOLOGIA EN EL DISCURS DE LA HISTÒRIA DE LA LLENGUA: EL TRACTAMENT DEL PROCÉS SOBIRANISTA*
}

\author{
IDEOLOGY IN THE DISCOURSE \\ OF THE HISTORY OF LANGUAGE: \\ THE TREATMENT OF THE SOVEREIGNTY PROCESS
}

\author{
Rosa Calafat Vila \\ Universitat de les Illes Balears \\ rosa.calafat@uib.cat
}

Resum: Aquest article analitza des de la teoria dels actes de parla els discursos socialitzats, entre 2016 i 20I9, per la premsa polaritzada amb ideologies en conflicte en el context de l'anomenat procés sobiranista a Catalunya i l'Estat espanyol. Per una banda, es destaquen, amb un enfocament pragmàtic, alguns dels termes que el llenguatge mediàtic ha creat dins l'esfera sobiranista per construir-ne el relat ideològic; per l'altra, s'estudia la deslegitimació que n'han fet els mitjans d'àmbit estatalista en la construcció del contrarelat.

En aquesta confrontació dialèctica argumentativa, els mitjans de comunicació, autèntics intermediaris sociocognitius entre el marc mental i el marc contextual, han socialitzat actituds lingüístiques a l'entorn de l'ús social de la llengua catalana, en tant que idioma en competència sociolingüística amb l'espanyol. El present estudi vol mesurar fins a quin punt aquestes creences són representacions socials lligades a una ideologia fonamental de grup $i$, alhora, constatar-ne les estratègies retòriques, especialment lèxiques, usades en les proposicions medul.lars d'ambdues esferes mediàtiques.

Paraules clau: procés sobiranista; ideologies mediàtiques; llengua i ideologia; català i castellà; bilingüisme i llengua catalana.

(*) Aquest article ha estat possible gràcies al projecte de recerca FFI20I6-80I9I-P (AEI/FEDER, UE), finançat pel Ministerio de Economía y Competitividad, i pel Grup de Recerca en Història de la Llengua Catalana de l'Època Contemporània (20I7 SGR I696), reconegut i finançat per l'AGAUR de la Secretaria d'Universitats i Recerca de la Generalitat de Catalunya. A més, aquest treball ha estat cofinançat parcialment per la Comunitat Autònoma de les Illes Balears, a través de la Direcció General de Política Universitària i Recerca, amb fons de la Llei de l'Impost sobre l'estada turística ITS 2017-006 (PRD2018/03). 
Rosa Calafat Vila

La ideologia en el discurs de la història de la llengua: el tractament del procés sobiranista

Abstract: This article uses speech act theory to analyse the socialised discourse in polarised media between 2016 and 2019, where ideologies conflicted with the so-called sovereignty process scenario in Catalonia and Spain. On the one hand, some of the terms created by language in the media with regard to the sovereignty process and constructing an ideological narrative are highlighted from a pragmatic approach; on the other, the discrediting used by state-wide media in constructing a counter-narrative is also analysed.

In this dialectic, belligerent confrontation, the media, authentic socio-cognitive intermediaries between psychological and contextual frameworks, have socialised linguistic attitudes around the social use of Catalan, as a language that competes both socially and linguistically with Spanish. This study attempts to measure up to what point these beliefs are social representations linked to a fundamental group ideology, whilst noting the rhetorical strategies, particularly lexicon, used in the central propositions of both spheres of media.

Keywords: sovereignty process; media ideology; language and ideology; Catalan and Spanish; bilingualism and Catalan.

cos es es

\section{INTRODUCCIÓ}

L'anomenat procés sobiranista del Principat de Catalunya arrenca, entre altres fets (Puigpelat 20I6: 203-239), de les pretensions d'autogovern, en bona part fallides, en la reforma de l'Estatut (2006). Aquest fracàs comportà un viratge social i, posteriorment, polític a favor de la independència (2012) de l'actual comunitat autònoma espanyola. ${ }^{1}$ Els mitjans de comunicació, en tant que intermediaris cognitius entre el poder social (propaganda política, lleis) i el públic (Graber 1976: 135; Bourdieu 1972 i 2000), s’han encarregat de legitimar i difondre el cos de creences de les ideologies confrontades en aquest procés (Gifreu 2018: 83; Cebrián 2004: I5), les quals, en referir-se al camp específic de la llengua, han normalitzat actituds lingüístiques en conflicte. ${ }^{2}$

Aquest escrit arreplega i estudia els discursos socialitzats per la premsa ideològicament polaritzada a propòsit d'aquests esdeveniments dins el període que va de 2016 a 20I9. Ens enfrontam a tres anys en què les actituds i creences al voltant del context

I. Atès l'objecte d'estudi, aquest article se cenyeix, fonamentalment, al Principat de Catalunya.

2. El fet d'haver d'analitzar des d'una perspectiva historiogràfica, capaç de donar compte del conjunt de pensaments lingüístics generats al voltant de la llengua catalana, un episodi factual tan immediat que inclou el temps present, compromet l'estudiós. Aquest ha de fer història de la llengua amb la mateixa llengua estudiada i de la qual és parlant. D'aquesta manera, la paradoxa lingüística i la de l'observador conflueixen en l'elaboració discursiva dels fets estudiats. 
sociolingüístic construeixen un relat amb un vocabulari específic que s'origina en l'esfera sobiranista amb una càrrega simbòlica plena i es desconstrueix en els mitjans estatalistes amb el recurs estilístic de la metàfora.

\section{METODOLOGIA}

Específicament, el corpus analitzat comença amb el «Manifest Llengua i República", signat el I4 d'abril de 20I6, i acaba l'octubre de 2019 amb la sentència del Tribunal Suprem als polítics catalans que lideraren els fets a l'entorn del primer d'octubre de 20I7. El constitueixen els textos periodístics recollits en la premsa escrita generalista catalana (El Punt Avui, Ara i Vilaweb, d'adscripció sobiranista) i espanyola (l'ABC i El Pais, de referent estatal), els productes discursius dels quals connoten creences ideològiques altament confrontades. Per això s'ha prescindit del discurs present a $E l$ Periódico i La Vanguardia, atès que tots dos diaris de bon principi optaren pel titular descriptiu (Gifreu 20I8: 67) i, d'altra banda, no signaren l'editorial/manifest que conjuntament rubricaren vint-i-dos mitjans en resposta de rebuig a l'empresonament dels polítics i dels líders socials del procés. ${ }^{3}$

S'han recopilat un total de cinc-cents articles, dels quals s'han analitzat els elements de titulació i el cos discursiu, encara que, en aquest escrit, s'hi reflecteixen bàsicament els continguts presents al titular i al subtitular atesa llur rellevància contextual. La tria s'ha fet a partir del sintagma de cerca "el procés i la llengua catalana». ${ }^{4}$ S'hi han prioritzat els articles d'opinió i els editorials, alhora que s'han restringit les notícies centrades en declaracions de partits polítics, així com les que feien incidència reiterada a un mateix esdeveniment. En l'anàlisi s'ha constatat que la producció discursiva al voltant dels conceptes cercats ha estat més fecunda en l'esfera mediàtica estatal. Per dos motius: primer, pel nombre d'articles que han respost a la cerca «el procés i la llengua catalana» en cadascuna de les dues esferes en contrast; i segon, perquè el lèxic i la gramàtica presents a $E l$ País i l' $A B C$ tenen, entre ells, matisos diferents, la qual cosa ha obligat a fer-ne una anàlisi diferenciada. En canvi, l'activitat discursiva de la premsa sobiranista amb referència als criteris de cerca ha estat menor i, a més, el llenguatge que s'hi utilitza no difereix entre un mitjà i l'altre.

3. Gifreu (20I8), en analitzar la resposta als fets d'octubre de 2017 a les portades de diaris de Madrid (ABC, El Mundo, La Razón i El País) i de Barcelona (La Vanguardia, El Periódico, El Punt Avui i Ara), constata l'afiliació al Govern central dels primers, enfront de, per una banda, l'adscripció sobiranista d'El Punt Avui i l'Ara, i la tendència al titular descriptiu de La Vanguardia i El Periódico.

4. La font de cerca han estat les hemeroteques digitals de cada mitjà.

Caplletra 71 (Tardor, 2021), p. 237-258 
Rosa Calafat Vila

La ideologia en el discurs de la història de la llengua: el tractament del procés sobiranista

Metodològicament, l'enfocament pragmàtic ens ha permès encarar la producció periodística com un acte de parla amb força il-locutiva lligat a l'acte perlocutiu de convèncer el lector (Bassols 2003a), en què el context, la intenció del parlant i els implícits són els elements que donen significat holístic al text. Al cap i a la fi, la història de la llengua és «un conjunt organitzat de productes discursius sobre l'evolució de la comunitat catalanoparlant en relació a les formes de comunicació, als elements verbals que hi ha fet servir i a les maneres amb què ha reaccionat emotivament $\mathrm{i}$ intel-lectiva» (Nicolás 1998: 79).

\section{EL CONTEXT DE LA LLENGUA CATALANA: DISCURSOS I IDEOLO- GIES EN ELS MITJANS}

Dins l'Estat espanyol, la llengua catalana inicia el segle xxi amb les reformes dels estatuts d'autonomia de Catalunya, el País Valencià i les Illes Balears. El 2006, Catalunya vota i aprova en referèndum el nou Estatut, ${ }^{5}$ sobre el qual, el 20Io, s'emet sentència d'inconstitucionalitat en I4 articles. Entre d'altres, es declara nul.la l'expressió preferent per a l'ús del català en els àmbits de l'administració pública i en els mitjans de comunicació. Quant al País Valencià, el 2006, la reforma no sols no implica nous drets i deures per a la llengua pròpia sinó que n’agreuja el problema onomàstic (Teodoro 2008: 139). En referència a les Illes, el 2007, la revisió estatutària no aconsegueix, tampoc, l'equiparació de drets i deures lingüístics entre el català i el castellà (Colom 2009: 302).

El que per a alguns havia de ser una oportunitat de tenir un redactat legal més favorable a l'estandardització de la llengua del territori no passava el llindar del continuisme en el millor dels casos. S'hi perpetuava, així, l'asimetria entre el castellà, única llengua oficial de l'Estat, ${ }^{6} \mathrm{i}$ el català. El redactat implicava seguir amb la institucionalització del bilingüisme, és a dir, amb usos socials restringits per al català ${ }^{7} \mathrm{i}$ la consegüent afectació en la conducta del parlant (Pradilla 2017: 402).

En el cas de Catalunya, és la resposta a unes pretensions estatutàries no acomplertes el que gesta el camí cap a la independència (Cardús 20I0: 18-19). Concretament,

5. El camí per arribar a l'aprovació comportà tres anys de discussions polítiques i retallades pel que fa a les aspiracions d'autogovern.

6. El supremacisme d'aquesta llengua era reivindicat, el 2008, al «Manifiesto por la lengua común», signat per l'elit intel-lectual del marc de referència estatalista.

7. Actualment, el català té àmbits d'ús amb presència limitada, <https://www.plataforma-llengua.cat/ que-fem/ambits-de-treball/justicia> (consulta: febrer 2020). 
la massiva manifestació de l'II de setembre de 2012 a Barcelona —organitzada, atenent les demandes socials, a través d'entitats cíviques com la històrica Ômnium Cultural (196I) o l'acabada de crear Assemblea Nacional Catalana (20I2) - hauria estat el detonant del viratge de la política autonòmica cap al procés sobiranista, coocurrència truncada amb el terme el procés. ${ }^{8}$ Les eleccions de 2015 donaven la majoria absoluta a les forces independentistes i, el juny de 20I7, el president de la Generalitat anunciava per al primer d'octubre la celebració d'un referèndum cap a la possible sobirania, el qual seria declarat il.legal per l'Estat. Aquesta data es convertia en el món de l'esfera periodística ${ }^{9}$ catalana en una col-locació neològica del tipus senyals de memòria (Pastor 2008): «L'I-O és un fet històric» (El Punt Avui, 17-04-2019). Els resultats del referèndum, favorables a la independència, obligaven el Parlament, el 27 d'octubre, a fer la Declaració unilateral d'independència (DUI), que no va tenir efectes. En resposta, de manera immediata, el Govern espanyol aplicava l'article 155 de la Constitució amb la destitució del Govern català i la dissolució del Parlament, a més de la convocatòria de noves eleccions autonòmiques per al 2I de desembre. Com a conseqüència, el president i part del Govern s'exiliaven a Bèlgica, i el vicepresident $i$ altres set membres del Govern eren empresonats, el 2 de novembre de 20I7. Prèviament, el I6 d'octubre, ho havien estat els presidents de les entitats cíviques Òmnium Cultural i ANC. Amb tot i amb això, els resultats de les eleccions autonòmiques del 2I de desembre atorgaven, un altre cop, la majoria absoluta als partits independentistes (Gifreu 20I8: 28-30). Finalment, l'octubre de 2019 el Tribunal Suprem espanyol dictava sentència definitiva de presó per als líders polítics i socials.

En aquest context es produeix l'activitat discursiva analitzada. El relat del procés sobiranista s'articula amb el llenguatge, expressió social activa (Burke 200r: 38; Lakoff 2008: 19) amb la qual els individus i els grups controlen els altres o s'hi resisteixen:

8. El mot procés s'ha consolidat com a terme denominatiu a totes dues esferes mediàtiques, amb un tractament oscil.lant entre el mot comú i el nom propi. Quant als mitjans estatals: La sentència del Procés és irreprotxable ( $A B C, 8-\mathrm{II}-20 \mathrm{I9})$, <https://sevilla.abc.es/sevilla/sevi-santiago-munoz-machado-dice-sentenciaproces-tecnicamente irreprochable-201911071956_noticia.html>); El "procés» a través de seis deformaciones $(A B C$, 24-II-20I9), <https://www.abc.es/espana/abci-proces-traves-seis-deformaciones-20I9II240304_noticia.html>); Naufragio delprocés (ElPaís, 7-92017), <https://elpais.com/elpais/2017/09/o6/opinion/1504723473_365302.html>); Hasta que empezó el Procés (ElPaís, 9-04-2018), <https://elpais.com/ccaa/2018/04/o7/catalunya/1523126568_021755. html >). Pel que fa als d'ideologia sobiranista, es reparteixen entre l'ús pràcticament exclusiu com a mot comú a Vilaweb i El Punt Avui (Judici contra el procés Vilaweb, etiqueta-dossier, <https://www.vilaweb.cat/etiqueta/ judici-contra-el-proces/>) i la preferència pel nom propi a l'Ara (Un diàleg sobre el Procés, 4-OI-20I8, <https:// www.ara.cat/opinio/dialeg-sobre-Proces_o_193720627I.html>) (consulta: febrer 2020).

9. El terme esfera periodística és sinònim de cultura periodística o representació ideològica de les actituds i creences socialment compartides a través dels productes textuals (Gifreu 2018: 89-90).

Caplletra 71 (Tardor, 2021), p. 237-258 
Rosa Calafat Vila

La ideologia en el discurs de la història de la llengua: el tractament del procés sobiranista

«Tout postulant au pouvoir s'efforce d'imposer son propre dictionnaire [...]. Parle dans ma langue, tu penseras comme moi» (Tournier 2002: 292). Entre aquestes pràctiques, s'hi inclouen les opinions sobre l'estatus social de la llengua catalana. Arran del «Manifest per un veritable procés de normalització lingüística a la Catalunya independent ${ }^{10}$ que el 2016 un grup d'intel.lectuals (Grup Koiné) publica al voltant de les creences de la nocivitat del mite bilingüista (Aracil 1982: 39-58) i la necessitat d'estandarditzar la llengua catalana a tots els àmbits d'ús, els mitjans de comunicació en conflicte ideològic difonen opinions i judicis de valor oposats al voltant del concepte bilingüisme. Així, els de l'esfera sobiranista incideixen en els efectes perjudicials per a l'ús lingüístic i la consciència del parlant de l'esmentada pràctica: «Enquestes lingüístiques i realitats cruels. A vegades, saber parlar català no implica parlar català» (Vilaweb, 20-03-20I6). Per contra, els mitjans estatalistes adverteixen del perill de trencar l'ordre bilingüista: «Luchas koinistas. Si el legislador decidiera que el catalán tiene que ser la lengua primordial, un entramado jurídico-político arrinconaría el castellano» (El Pais, I3-04-2016).

Els mitjans de comunicació, tant els sobiranistes com els estatalistes, generen opinions avaluatives entorn del procés, per la qual cosa es procuren un vocabulari amb significació pragmàtica oposada (Vidal 2015): ${ }^{11}$ "Con permiso de Kafka [...] denuncia la perversión del lenguaje que vienen realizando los nacionalistas» $(A B C$, I2-04-20I8); «La lengua como víctima en Cataluña. [...]. La violencia también daña a las palabras. Cómo no estremecerse ante una locución como "tsunami democrático" " (El País, 28-IO-2019). En aquest enfrontament dialèctic, els primers, com a creadors de la realitat anomenada procés sobiranista, són proactius en els recursos lèxics, mentre que els segons s'ocupen, fonamentalment, de deslegitimar el significat simbòlic del llenguatge de l'esfera sobiranista. D'aquesta manera, quan els periòdics del procés fan ús del neologisme estilístic (Veny I99I: 25), eufemístic i connotat culturalment, els mitjans estatalistes es decanten per la metàfora conceptual. Així, el terme desconnexió serà l'eufemisme d'alliberació per als primers (Vidal 2015: 59-60), significat simbòlic que els altres eliminaran amb el recurs transparent de la metàfora: «Desconectar: El eje de la campaña ha consistido en la idea de que Cataluña se desconectaría como si fuera un frigorífico» (El País, 22-II-20I7). Si per a uns la col-locació dret de decidir, ${ }^{12}$ amb la variant dret a decidir, evoca una creença positiva, la maquinària de referent

IO. A <http://llenguairepublica.cat/manifest> (consulta: febrer 2020).

II. Quant a l'ús dels mots en el relat dels fets d'octubre, vegeu, entre d'altres, l'article El lèxic a judici (El Punt Avui, 2I-03-2019).

I2. Des de l'esfera política es popularitza la col-locació dret de decidir el 20 Iо. 
estatalista la resignificarà negativament, tot argumentant que aquest privilegi implicaria una injustícia per al conjunt dels ciutadans de l'Estat (El País, 22-II-20I7). Així, al mot exili — referit als polítics catalans—, li correspondrà «fuga»; a procés democràtic, "referèndum il.legal» (El País, 26-03-2018); a dret de llibertat d'expressió, "delicte d'odi» (Vilaweb, 9-04-20I8). El compost sinàptic presos politics d'ús a la premsa d'esfera catalana — «Un programa de ràdio per als presos polítics» (El Punt Avui, 25-12-2019) — es converteix en un sintagma transparent per als mitjans de factura estatal: "No son presos políticos, son políticos presos» (El País, 26-03-20I8). El terme llengua pròpia, per referir-se a la llengua catalana en oposició al que és extern, entès pels sobiranistes com «la imposició politicojurídica del castellà a Catalunya» (Grup Koiné), adquirirà nova significació en el vocabulari mediàtic d'esfera estatalista: "Los catalanes tienen dos lenguas $\operatorname{propias}^{13}$ (al menos): el catalán y el castellano» (El País, 22-II-20I7).

De la mateixa manera que el llenguatge evoca inferencialment les creences que les instàncies legitimadores d'ideologia socialitzen, les imatges (banderes, llaços o altres objectes icònics) també ho fan (Van Dijk 2003: 49). Així, si el floc groc ha estat l'estendard sobiranista a favor dels líders empresonats del procés: «El llaç groc torna a la façana del Parlament de les Illes Balears. [...] per demanar l'alliberament dels presos polítics» (Vilaweb, II-09-20I9), els mitjans de referència estatalista s'encarreguen de deslegitimar-ne el simbolisme:

Enciclopedia Catalana incluye el icono del «procés» como símbolo del catalanismo [...]. Si un perro lleva un lazo amarillo no se acerque. Avisa que hay un problema: el perro está enfermo, en celo, tiene problemas de comportamiento, es nervioso o simplemente miedoso. (El País, 22-06-2019)

La teoria dels actes de parla proposada per Austin (I962) i reformulada per Searle (1969) es fonamenta en la intenció (intencionalitat) del parlant/escrivent, el qual és, alhora, un agent actiu de propietats cognitives i socials. D’aquesta manera Searle, completant Grice (1957), dirà que el significat és més que un assumpte d'intenció, és un assumpte de convenció. Aquesta es conforma de les representacions mentals compartides pels membres d'un grup, que en el cas estatalista englobaria creences avaluatives, legitimades dels Decrets de Nova Planta ençà (Ferrer i Gironès 2000) a l'entorn d'actituds lingüístiques supremacistes, amb opinions i judicis de valor negatius cap a la llengua catalana i els seus parlants, en tant que parlants: ${ }^{14}$

I3. El sintagma llengua pròpia és legalment establert a l'article 6 de l'Estatut d'Autonomia de Catalunya (2006), que és una llei orgànica de l'Estat.

I4. L'actitud secessionista seria una de les derivades de la ideologia anticatalanista al voltant de la qual s'aglutinen les creences avaluatives a favor de la llengua majoritària: «Imposición de la lengua vernácula en actos

Caplletra 71 (Tardor, 2021), p. 237-258 
El cantaor Miguel Poveda [...] haciendo un chiste catalanófobo al recitar la letra de un fandango en catalán para demostrar que así «ni pega ni llega» [...], al tiempo que afirma que no podría ser independentista basándose en los orígenes no catalanes de su madre y su padre, amén de que está siempre «viajando por todo el mundo». [...] El propio Manu Sánchez continúa la senda del humor catalanófobo con esta explicación histórica: «y si los catalanes declaran la independencia es porque desgrava; si no, la hubieran hecho en negro». (Rodríguez 20I7: 63-64) ${ }^{15}$

La historiografia castellana ha socialitzat la creença de la superioritat natural del seu idioma (Moreno Cabrera 2008). En considerar aquest pensament abstracte com la base del coneixement compartit d'aquesta cultura, les opinions que se'n deriven són avaluades pels membres del grup no com un producte ideològic — aquest ho seria si l'esmentada idée force fos situada a nivell comparatiu amb altres ideologies — sinó com a creença vertadera, ${ }^{16}$ de caràcter permanent i implícit (Van Dijk 1999: 74), «una casa común de la cual no cabe excluir a nadie», enfront de la nació cultural representada per l'extinta llengua catalana: «el castellano es la lengua mayoritaria - y comúndel $55 \%$ de los catalanes, frente al $32 \%$ que tiene el catalán como lengua materna» (El Pais, 27-09-2015).

D'aquesta manera, el nacionalisme català no s'encara a un nacionalisme espanyol, sinó a una creença comuna, a un implícit pressuposat i inqüestionable articulat a través de la llengua castellana. Qualsevol oposició a tal certesa és per se manifestació de discòrdia. D'aquesta manera, el procés sobiranista i la llengua catalana representarien els contravalors de la creença: «Peor sería si utilizáramos la lengua, su promoción y su defensa como instrumento para un proyecto político como es la secesión de Cataluña» (El País, 7-07-2019). És el poder simbòlic del banal nationalism o de la ideologia en sentit dèbil (Bobbio 198r: 755; Billig 1995), del qual no cal ni parlar atesa la seva naturalesa inqüestionable, en contrast amb el hot nationalism, reivindicatiu i, per tant, marcadament ideològic:

públicos, exclusión de empresas que facturen en español, todo ello acompañado de un progresivo aislamiento, cada vez menos sutil, de cualquier voz discrepante» (Las Provincias, I9-II-20I6, a <https://www.lasprovincias. es/comunitat/opinion/20I6II/20/multilinguismo-inmersion-construccion-identidades-20I6III92334I3-v.html>, consulta: març de 2020).

I5. Rodríguez (20I7: 57-75) analitza els tòpics anticatalanistes al voltant dels conceptes sobirania i llengua, que el 28 de febrer de 2016 foren reproduïts per la televisió autonòmica andalusa amb motiu del dia oficial d'Andalusia.

I6. La ideologia postfranquista fonamentarà el coneixement d'aquesta creença en el patriotisme constitucional, que no es basa en fets històrics, sinó fonamentalment en el valor suprem de la democràcia plasmat en la Carta Magna (Puigpelat ror6: 216). 


\begin{abstract}
En Cataluña nueve de cada diez inspectores son nacionalistas o guardan silencio [...] En la educación catalana se dan situaciones constitutivas de falta grave y muy grave que quedan impunes, [...] que en clase se les haga fabricar una bandera "estelada», indicando a los alumnos que es la bandera de una nación libre, o que se induzca a los estudiantes a huelgas nacionalistas. Estos casos y muchos otros fracturan claramente la preceptiva neutralidad e imparcialidad de la institución educativa. ( $A B C$, 17-12-2019)
\end{abstract}

Certament, la legitimació ideològica d'unes creences grupals sobre unes altres es basa en el supòsit indiscutible que uns grups mereixen uns avantatges sobre els altres (Van Dijk 2003: 48). La història contemporània del català s'escriu amb el relat confrontat de dues ideologies lingüístiques, la força simbòlica de les quals no és equilibrada, pels mateixos avatars que la història general explica.

\title{
4. EL PROCÉS SOBIRANISTA ILES ACTITUDS LINGÜÍSTIQUES: ESFERES MEDIÀTIQUES CONFRONTADES
}

La distinció entre la situació comunicativa, nombre indeterminat de fets susceptibles de ser pràctica discursiva, i el context, elements relacionats indefectiblement amb l'acte discursiu concret, esdevé cabdal (Casetti 1980: 194). En el tomb de la pràctica política cap al sobiranisme, l'estandardització de la llengua catalana ha centrat el discurs en debatre si el nou ordenament constitucional hauria d'atorgar també l'estatus de llengua oficial al castellà. Tanmateix, totes les veus en conflicte s'avindrien a reservar funcions exclusives per a la llengua territorial (Sendra \& Vila 2016: 46). La diferència del debat actual en relació amb les històriques reivindicacions del catalanisme polític rauria en el fet que per primer cop la qüestió de la llengua esdevindria un tema secundari en el procés: «Llengua prescindible. En el procés cap a la independència de Catalunya, la llengua catalana no hi té la més mínima importància, rellevància o funció icònica» (El Punt Avui, 9-09-2019). Des de l'esfera política sobiranista s'intentaria evitar així "els aspectes conflictius de la relació entre el castellà i el català» (Sendra \& Vila 20ı6: 36), encara que els estudis sobre la població que s'adhereix al projecte independentista demostrin la correlació entre aquest i l'ús de la llengua catalana (Ribera 20I7; Fabà \& Torres-Pla 20I7).

D'altra banda, les opinions presents als mitjans estatalistes al llarg del període estudiat semblen no haver innovat el discurs, estructurat a l'entorn de la ideologia monolingüista que des del segle Xviı han practicat els governs espanyol i francès. La llengua de l'estat és la creença absoluta amb valor moral sota la qual s'estructura

Caplletra 71 (Tardor, 2021), p. 237-258 
Rosa Calafat Vila

La ideologia en el discurs de la història de la llengua: el tractament del procés sobiranista

la mateixa idea d'estat (Boyer I999; Calafat 20I7). ${ }^{17}$ És així com el 2010 s'inicia «una llarga batalla jurídica i mediàtica contra el català a l'escola» (Mayans 2019: I89), àmbit en què la llengua catalana hauria aconseguit una certa consolidació com a llengua vehicular (Arenys 2007: 13-28).

Entre el 2016 i el 20I9, s'observa com l' $A B C$ i El País difonen productes discursius al voltant de creences, opinions i valors propis d'una actitud lingüística supremacista englobada en el marc de la ideologia monolingüista. Ara bé, tots dos mitjans usen estratègies enunciatives diferents per tal de socialitzar les esmentades opinions. Mentre que l' $A B C$ victimitza el castellà, amenaçat pel català i per la seva implantació en l'àmbit escolar, el diari El País es decanta per emfasitzar el valor moral del supremacisme i la bondat del bilingüisme.

El diari $A B C$ realça el contrast retòric entre les dues esferes culturals en disputa amb l'ús dels pronoms díctics. Per una banda, hi ha el Nosaltres, a través de la nominalització del subjecte simbòlic, el castellà; i, per l'altra, l'Ells, la llengua dels quals no és esmentada als titulars. Les proposicions medul.lars ${ }^{18}$ que conformen les opinions i creences de l'actitud supremacista en aquest mitjà usen el llenguatge metafòric de la guerra, propi de les discussions (Lakoff \& Johnson I998; Bassols 2003b):

\footnotetext{
«Por pedir más castellano he tenido que vender mi negocio y cambiar de colegio a mis hijos» $(A B C, \mathrm{I} 5-04-2016)$

«Omitir y sancionar al castellano» (ABC, 24-12-2016)

«En defensa de las lenguas comunes» $\left(A B C \mathrm{I}_{\mathrm{13}-05-2017}\right)$

"Cerco al castellano en Cataluña» ( $A B C$ I8-07-2017)

«El desamparo del castellano» (ABC, 4-03-20I8)

«Los CDR boicotean una manifestación en favor del castellano en Cataluña» ( $A B C, \mathrm{I} 6-09-2018)$

«El constante desprecio al castellano en los programas de TV3" (ABC, 30-IO-2018)

"Presión secesionista en las aulas catalanas. "Profesora, ¿puedo llorar en castellano?"” ( $A B C$, 19II-20I8)

«Los radicales organizan comandos para asaltar Barcelona» ( $A B C$, I4-I2-20I8)

«Los nacionalismos llevan años envenenando el debate lingüístico» ( $A B C$, I2-03-2019)
}

17. La llengua de l'estat té un alt valor moral, tal com es fa palès a la pregunta vint-i-nou de l'enquesta de l'abbé Grégoire (I794): «Quelle seroit l'importance religieuse et politique de détruire entièrement ce patois?». D'altra banda, el I789, el síndic personer, Ruiz de la Torre, funcionari espanyol destinat a Mallorca, recomana la necessitat d'estendre-hi la llengua castellana per tal d'evitar mals morals a l'Estat: «Todo será ignorancia y preocupaciones nocivas al Estado y la causa pública, ni se harán progresos en las artes y ciencias ni mejorarán las costumbres, algo góticas y africanas aquí» (Calafat 20I7: I7I).

I8. Marcam en cursiva els mots que connoten la ideologia o conjunt d'idees socialitzades per a cadascuna de les esferes mediàtiques. 
«Sistemática erradicación del castellano. [...] en el sistema educativo catalán: el castellano es peor tratado que el inglés» $(A B C$, 9-03-2019)

"Animadversión al castellano» $(A B C, 22-03-2019)$

"¿A qué nos enfrentamos?» ( $A B C$, 30-09-2019)

«Mordaza a la lengua oficial. Crece el acoso al castellano, lengua oficial del Estado a la que los nacionalistas no dejan de darle mala vida. Y nadie hace nada» $(A B C, 24-11-2019)$

L'aparent inconsistència entre la manca de recursos legals de l'oponent davant el poder factic de l'Estat — «Suspenderemos la Generalitat hasta la derrota del golpismo» ( $A B C$, 30-03-2018) — i el suposat perill que la llengua catalana semblaria representar per a l'ús social del castellà esdevé irrellevant:

La lengua de todos, arrinconada en Catalunya. [...] La lucha por el bilingüismo en el sistema educativo catalán se está perdiendo antela pasividad del Estado. La expulsión del castellano de las aulas nunca fue una exageración de cuatro familias de "charnegos», sino un instrumento para desarraigar a los jóvenes catalanes de cualquier vínculo cultural, social e intelectual con el resto de España. (ABC, 23-05-2019)

Per altra banda, El País opta per l'expressió pública d'opinions articulades a l'entorn del tòpic de la bondat intrínseca dels valors comuns fonamentats en la tríada set-centista dels conceptes nuclears llibertat, fraternitat i igualtat: «República sin fraternidad. [...] sustrato ideológico y cultural común de la república imaginada a que aspira una parte importante de la política catalana [...] una operación inversa al significado moral del antifranquismo" (El País, 19-03-2019). Aquest mitjà de comunicació construeix el seu discurs en les creences següents: Primera, el nacionalisme català és precientífic (El País, 27-II-20I9), localista (El País, 8-09-2017) i desestabilitzador: «El peligro de que la rebelión interminable termine generando una división también interminable entre las dos cataluñas enfrentadas» (El País, 29-10-2018); "Daños del "procés" a Cataluña» (El País, I-IO-20I9). Segona, la vindicació de la llengua catalana, més enllà del bilingüisme social, és un valor anacrònic, nociu a l'estat:

"Contra los catalanes. El manifiesto monolingüista amenaza la convivencia y la inmersión escolar. Ahora estos firmantes rompen la (perfectible) paz idiomática, atacan al castellano [...] zahieren a la inmensa mayoría de catalanes de carne y hueso, que encuentra en el pluralismo abono de convivencia y progreso» (El País, 6-04-2016)

«Identificar nación y lengua, como corresponde a la decimonónica primavera de los pueblos, es un anacronismo peligroso» (El País, 26-02-2018)

«La tercera Cataluña. En cuanto a la lengua, fue precisamente la huida hacia delante de la segunda legislación lingüística pujolista, de clara vocación monolingüista» (El País, 8-04-2018) 
Rosa Calafat Vila

La ideologia en el discurs de la història de la llengua: el tractament del procés sobiranista

\begin{tabular}{|l|l|}
\hline \multicolumn{2}{|c|}{ El llenguatge de l'esfera estatalista } \\
\hline \multicolumn{1}{|c|}{$A B C$} & \multicolumn{1}{c|}{ El País } \\
\hline $\begin{array}{l}\text { sancionar al castellano } \\
\text { en defensa de las lenguas comunes } \\
\text { cerco al castellano }\end{array}$ & $\begin{array}{l}\text { dos catalunas enfrentadas } \\
\text { manifiesto monolingüista } \\
\text { amenaza a la convivencia }\end{array}$ \\
$\begin{array}{l}\text { los CDR boicotean una manifes- } \\
\text { tación favor del castellano en } \\
\text { Cataluña }\end{array}$ & $\begin{array}{l}\text { progrismo, abono de convivencia y } \\
\text { nacionalismo y lengua, anacronismo } \\
\text { peligroso }\end{array}$ \\
desprecio al castellano & $\begin{array}{l}\text { legislación lingüística pujolista, vo- } \\
\text { presión secesionista } \\
\text { envenenando el debate lingüístico } \\
\text { erradicación del castellano } \\
\text { animadversión al castellano }\end{array}$ \\
nos enfrentamos & \\
acoso al castellano & \\
derrota del golpismo & \\
la lengua de todos & \\
lengua arrinconada & \\
expulsión del castellano & \\
\hline
\end{tabular}

Quant al'esfera mediàtica catalana, l'actitud lingüística defensiva crea un discurs al voltant d'opinions i creences contraargumentatives de la ideologia estatalista. Si bé el 20I6, amb motiu de la publicació del document «Manifest Llengua i República», els mitjans de comunicació, especialment Vilaweb, publicaven un conjunt de textos $\mathrm{amb}$ referència al català com a element identificatiu del grup i de creença amb valor d'ús general, ${ }^{19}$ entre el 2017 i el 2019 els articles d'opinió i els editorials que tracten l'ús social de la llengua catalana ho fan al voltant del prejudici del bilingüisme i les seves nefandes conseqüències. Els recursos gramaticals i lèxics del discurs lingüístic del marc sobiranista pertanyen al camp metafòric del conflicte amb visió de derrota, en què l'ús retòric de la prosopopeia permet concebre la llengua com un ésser viu, el destí del qual sembla apuntar cap a l'extinció. Els temes al voltant de la macroproposició esmentada es fan evidents en quatre judicis generals, entre els quals destaca l'apartat dedicat a la contraargumentació.

El primer és l'opinió a propòsit de la nocivitat del bilingüisme social en termes de retrocés en l'ús de la llengua catalana: «El català, en fora de joc. Només entre un $6 \%$ i un $8 \%$ de les joguines que hi ha al mercat fan servir la llengua catalana» (Ara,

19. Alguns dels títols d'aquest escrit són: «La llengua i el Procés» (Vilaweb, I5-04-2016), «La República també... ha de salvar-nos els mots» (Vilaweb, 02-04-2016) (consulta: febrer 2020). 
4-OI-20I6); "Qüestió de llengua. [...] És el model triat i el model és un fracàs. Des d'Alacant fins a Barcelona, la reducció de parlants en els grans centres urbans resulta fefaent» (El Punt Avui, 30-07-2016); "El català ha perdut 300.000 parlants habituals a Catalunya en deu anys» (Vilaweb, 8-06-2018); "El judici i la llengua dels aborigens» (Ara, I4-09-2019); "La discriminació del català al jutjat» (El Punt Avui, 19-09-2019). El segon fa referència als efectes d'aquest bilingüisme sobre el parlant i la seva consciència lingüística, la qual no és homogènia sinó que respon a les fluctuacions pròpies del conflicte lingüístic:

«Denuncien que un professor s'enfronta a 600 euros de multa per parlar en català a dos policies a l'Aeroport del Prat» (Vilaweb, 23-03-2017)

«La cultura en català només ens té a nosaltres» (Vilaweb, 4-04-20I7)

"L'any Pompeu Fabra arrenca amb una crida a enfortir la llengua catalana» (Vilaweb, 2I-O2-20I8)

«Si un sol espectador ho demana. Al final, el missatge més clar que donen els politics catalans - per a les Espanyes i més enllà- és que la llengua pròpia del país és negligible, substituïble, inútil quan es tracta de comunicar "de veritat" (Vilaweb, 8-04-2019)

"Quan només dir "bon dia" et costa dos-cents mil euros. En qüestions de llengua i de respecte als drets lingüístics dels catalanoparlants, és alarmant constatar com va degradant-se la situació» (Vilaweb, 30-07-2019)

El tercer tema és el futur extint de la llengua catalana: «Isabel-Clara Simó: "La nostra llengua està en perill de mort" " (Vilaweb, 7-02-2016); "Quim Monzó, premi d'honor: "Anem cap a una 'irlanditzaciô" del català" (Vilaweb, 7-03-20I8); "El català no mor, el matem. Dimitim de la llengua. I la dimissió convertirà el català en una llengua zombi i a nosaltres en morts vivents» (Ara, 27-OI-20I9); "Un idioma en retirada» (I i II) (El Punt Avui, 23-07-2019/30-07-2019). El quart element que predomina en els textos publicats pels mitjans de l'òrbita sobiranista és el contrajudici a les opinions i creences de l'esfera estatalista:

"En el tercer aniversari (i tres mesos) del manifest Koiné "El terror d'admetre cap retret contra un simbol de la colonització els porta a embolicar-lo amb la cel-lofana de la correcció política”" (Vilaweb, 04-04-2017)

«El català (NO) és la llengua pròpia de Catalunya» (El Punt Avui, 3-08-20I7)

«Catalunya (NO) ha estat discriminada per la llengua. Diplocat acaba de documentar 45 nous episodis de catalonofobia exercida per funcionaris de l'Estat» (El Punt Avui, 5-08-20I7)

«El que més odien és la llengua. El fonament, l'emblema i l'objectiu últim del nacionalisme espanyol ha estat i és sempre el mateix: l'eliminació de la llengua catalana» (Ara, I5-II-20I7)

"Amenaces contra la llengua. Els catalans surten al carrer. "No ens dividiran?"” (El Punt Avui, I6-02-2018)

«Catalunya fa nosa. No han trigat gaire a fer-se realitat les previsions que el PP s'ha proposat anorrear Catalunya fins a destruir-la» (El Punt Avui, 13-07-2018) 
"La llengua de la causa general contra el dret a l'autodeterminació. La justícia espanyola menysté la nostra llengua; per a ella és una llengua subsidiària que fa nosa» (Ara, 9-OI-20I9)

"El català i l'estatus de llengua antipàtica. L'últim producte sorgit dels laboratoris de destrucció de l'autoestima és la idea que l'independentisme ha fet antipàtica la llengua catalana» (Ara, I4-07-2019)

\begin{tabular}{|c|c|c|}
\hline \multicolumn{3}{|c|}{ El llenguatge de l'esfera sobiranista } \\
\hline Vilaweb & El Punt Avui & Ara \\
\hline $\begin{array}{l}\text { el català ha perdut } \\
\text { multa per parlar en català } \\
\text { crida a enfortir la llengua } \\
\text { catalana } \\
\text { el missatge més clar que do- } \\
\text { nen els polítics catalans } \\
\text { la llengua pròpia del país és } \\
\text { negligible } \\
\text { dir "bon dia" et costa dos- } \\
\text { cents mil euros } \\
\text { degradació de la situació } \\
\text { perill de mort } \\
\text { irlandització del català } \\
\text { idioma en retirada } \\
\text { símbol de la colonització }\end{array}$ & $\begin{array}{l}\text { reducció de parlants } \\
\text { discriminació del català al } \\
\text { jutjat } \\
\text { idioma en retirada } \\
\text { catalanofobbia } \\
\text { amenaces contra la llengua } \\
\text { no ens dividiran }\end{array}$ & $\begin{array}{l}\text { el català, fora de joc } \\
\text { llengua dels aborígens } \\
\text { matar el català } \\
\text { el català, llengua zombi } \\
\text { morts vivents } \\
\text { odiar la llengua } \\
\text { objectiu últim del nacionalis- } \\
\text { me espanyol } \\
\text { eliminació de la llengua ca- } \\
\text { talana } \\
\text { la llengua de la causa general } \\
\text { dret a l'autodeterminació } \\
\text { llengua antipàtica }\end{array}$ \\
\hline
\end{tabular}

\section{CONCLUSIONS}

Entre 20I6 i 2019 transcorren alguns dels fets més representatius de l'anomenat procés sobiranista. Aquest marc contextual provoca l'enfrontament discursiu entre dues esferes mediàtiques amb capacitat perlocutiva, la polarització ideològica de les quals resta condicionada per l'adscripció sobiranista d'El Punt Avui, Ara i Vilaweb, i l'estatalista dels diaris El País i $A B C$. Aquests mèdia, intermediaris sociocognitius entre el poder polític i el públic, s’adhereixen al vocabulari propi de la força legitimada que representen. Així, en el relat del procés, els sobiranistes es mostren productors i difusors actius del camp semàntic que posa nom al relat, en què lèxicament destaca el neologisme estilístic de funció simbolitzadora. Per contra, els d'adscripció estatalista usen la metàfora conceptual en què la correlació entre el domini d'origen i el de destinació buida de càrrega cultural el relat sobiranista.

El debat al voltant de l'estatus de la llengua catalana en el procés sobiranista s'ha centrat en la macroproposició o tòpic rellevant del bilingüisme i la seva aplica- 
ció a Catalunya, les opinions i creences al voltant del qual han mostrat ideologies en contrast. Per una banda, els mitjans estatalistes s'han convertit en socialitzadors de l'actitud lingüística supremacista adscrita a la ideologia monolingüista, com a creença no contrastiva. En aquest sentit, s'hi han generat titulars i subtitulars a favor del bilingüisme social a Catalunya. L'ensenyament n'ha estat el camp de batalla, en tant que àmbit d'ús amb presència vehicular de la llengua catalana. Ara bé, els dos mitjans estatalistes han optat per estils discursius diferenciats. Per una banda, l' $A B C$ ha emprat la metàfora del lèxic de la guerra i n'ha emfasitzat el contrast grupal amb la dixi pronominal. Per l'altra, El Pais ha fet ús de l'argumentació entorn dels valors morals, hereus de la ideologia lingüística del Set-cents de la llengua comuna.

Quant als discursos d'adscripció sobiranista, s'han articulat al voltant de les opinions i creences sobre el prejudici del bilingüisme social, la pràctica del qual abocaria la llengua catalana al decés. Així, la ideologia lingüística en la cultura catalana s'especificaria en una actitud lingüística defensiva més que no en una de constructiva. En aquest sentit, $i$ tret del debat que el 2016 es produí a propòsit de la conveniència, $o$ no, del fet que la llengua catalana esdevingués l'única oficial en una futura República, el procés sobiranista ha estat poc proactiu en la planificació lingüística. Pel que fa als recursos estilístics, l'ús del vocabulari de la guerra ha ocupat el camp lèxic dels titulars i subtitulars. A diferència de l' $A B C$, que emfasitza el combat entre totes dues llengües en disputa, el discurs sobiranista es construeix semànticament a l'entorn de la derrota.

Rosa Calafat Vila

Universitat de les Illes Balears

rosa.calafat@uib.cat

ORCID 0000-0003-I2I2-OI4I

\section{REFERÈNCIES BIBLIOGRÀFIQUES}

Aracil, L. (1982) Papers de sociolingüística, Barcelona, Edicions de la Magrana. Areny, M. (2007) «La immersió lingüística a Catalunya: un model per a Europa», Europa de les nacions, 65, p. 13-28.

Austin, J. L. (1982 [ia ed. I962]) Cómo hacer cosas con palabras, Barcelona, Paidós.

Bassols, M. (2003a) «Pragmàtica i anàlisi del discurs», Noves SL. Revista de Sociolingüistica, 4 (hivern), p. I-8.

- (2003b) «La guerra dels mots i els mots de la guerra. La invasió d'Iraq a través del discurs periodístic», Anàlisi, 30, p. 187-204.

Caplletra 71 (Tardor, 2021), p. 237-258 
Rosa Calafat Vila

La ideologia en el discurs de la història de la llengua: el tractament del procés sobiranista

Billig, M. (I995) Banal nationalism, Londres, Sage [Traducció al català, Nacionalisme Banal, València, Afers / Universitat de València, 2006].

Воввіо, N. (198I) «Ideología», dins Diccionario de Política, Mèxic, Siglo XXI Editores, p. $755-770$.

Bourdieu, P. (1972) «Les stratégies matrimoniales dans le système de reproduction», Annales, 4-5, p. IIO5-II27.

- (2000) Esquisse d'une théorie de la pratique, précédé de trois études d'ethnologie, kabyle, París, Editions du Seuil.

Boyer, H. (I999) «La Revolució francesa a la recerca de l'unilingüisme», dins F. Feliu \& C. Juher (eds.), La invenció de les llengües nacionals, Barcelona, Quaderns Crema, p. IO3-I22.

Burke, P. (200I) Hablar y callar. Funciones sociales del lenguaje a través de la historia, Barcelona, Gedisa Editorial.

Calafat, R. (20I7) «Les lleis de Carles III a Mallorca: ideologia i llengua en l'acció funcionarial», Revista de Llengua i Dret, 68, p. I57-I74.

Cardús, S. (2010) El cami de la independència, Barcelona, La Campana.

CAsetTi, F. (1980) Introducción a la semiótica, Barcelona, Editorial Fontanella.

Cebrián, M. (2004) La información en televisión. Barcelona, Gedisa.

Colom, B. (2009) «La reforma de l'Estatut d'autonomia de les Illes Balears de 2007 i la llengua catalana», Revista de Llengua i Dret, 52, p. 275-326.

FABÀ, A. \& J. Torres-Pla (20I7) «El suport a la independència de Catalunya segons la llengua d'identificació i altres variables (2OII-20I5)», Treballs de Sociolingüistica Catalana, 27, p. 30I-3I9.

Ferrer i Gironés, F. (2000) Catalanofobia. El pensament anticatalà a través de la història, Barcelona, Edicions 62.

Gifreu, J. (20I8) El quartpoder i la independència. La batalla mediàtica per l'I d'octubre, Barcelona, Angle Editorial.

Graber, D. A. (I976) Verbal behavior and politics, Urbana, Chicago / Londres, University of Illionis Press.

Grice, H. P. (1957) «Meaning», Philosophical Review, 67, p. 377-388.

Lakoff, G. (2008) No pensis en un elefant, Barcelona, Viena Edicions.

Lakoff, G. \& M. Johnson (1998) Metáforas de la vida cotidiana, Madrid, Cátedra.

Mayans, P. (2019) Cròniques negres de català a l'escola, Barcelona, Edicions del 1979.

Moreno Cabrera, J. C. (2008) El nacionalismo lingüistico. Una ideología destructiva, Barcelona, Ediciones Península.

Nicolás, M. (1998) La història de la llengua catalana: la construcció d'un discurs, València / Barcelona, Institut Interuniversitari de Filologia Valenciana / Publicacions de l'Abadia de Montserrat. 
Pastor, L. (2008) Redacció periodística, Barcelona, UOC.

Pradilla, M. A. (20I7) «Després de la tempesta arriba la calma? A propòsit de la dinamicitat de la política i la planificació lingüístiques en l'àmbit de la llengua catalana», Estudis Romànics, 39, p. 399-4I4.

Puigpelat, F. (20I6) Breu història del nacionalisme espanyol. De la Constitució de I8I2 a la probibició del $9-N$, Barcelona, Angle Editorial.

Ribera, M. C. (20I7) «La llengua i el sentiment de pertinença dels habitants de Catalunya a principis del segle XXI", Treballs de Sociolingüistica Catalana, 27, p. 235-254.

Rodríguez, M. (20I7) «28F, catalanofobia y unidad de destino: la Trinidad discursiva en la estrategia comunicativa del "Susanato"”, dins M. Bermúdez \& R. D. Macho (eds.), Análisis del discurso mediático: un enfoque multidisciplinar, Sevilla, Ediciones Egregius.

SeArLe, J. (2005 [Ia ed. 1969]) «¿Qué es un acto de habla?», dins L. M. Valdés (compilador), La búsqueda del significado, Madrid, Editorial Tecnos, p. 43I-447.

Sendra, M. \& F. X. VIla, (20I6) «L'estatus de les llengües a la República Catalana», Els Marges, io8, p. 33-50.

Teodoro, M. (2008) «La llengua a l'Estatut valencià. Comentaris a les disposicions lingüístiques del nou Estatut valencià», Revista de Llengua i Dret, 49, p. I25-I4I. Tournier, M. (2002) Desmotsen politique: Propos d'étymologie sociale, Lió, Ens Éditions. VAN DijK, T. A. (1999) Ideología. Una aproximación multidisciplinar, Barcelona, Gedisa Editorial.

- (2003) Ideología y discurso, Barcelona, Ariel.

VenY, J. (1991) Mots d'ahir i d'avui, Barcelona, Empúries.

VIDAL, P. (20I5) Manual del procés. Vocabulari imprescindible de combat, Barcelona, Angle Editorial.

\section{ANNEX. ARTICLES DEL CORPUS CITATS}

$A B C$

- «Por pedir más castellano he tenido que vender mi negocio y cambiar de colegio a mi hijos» (I5-04-2016). A <https://www.abc.es/espana/catalunya/politica/abci-pedirmas-castellano-tenido-vender-negocio-y-cambiar-colegio-hijos-201604070300_ noticia.html> (consulta: febrer 2020).

- «Omitir y sancionar el castellano» (24-I2-20I6). A <https://www.abc.es/espana/ catalunya/abci-omitir-y-sancionar-castellano-201612282039_noticia.html> (consulta: febrer 2020). 
- «En defensa de las lenguas comunes» (I3-05-20I7). A <https://www.abc.es/espana/ catalunya/abci-defensa-lenguas-comunes-201705131028_noticia.html> (consulta: febrer 2020).

- «El desamparo del castellano» (4-03-2018). A <https://www.abc.es/opinion/abcidesamparo-castellano-201803040604_noticia.html> (consulta: febrer 2020).

- «Suspenderemos la Generalitat hasta la derrota del golpismo» (30-03-20r8). A <https://www.abc.es/espana/abci-ignacio-garriga-suspenderemos-generalitathasta-derrota-golpismo-201903300139_noticia.html> (consulta: febrer 2020).

- "Violencia también es intimidar, excluir y crear listas negras en Cataluña» (I2-04-20I8). A <https://www.abc.es/cultura/libros/abci-jordi-canal-violenciatambien-intimidar-excluir-y-crear-listas-negras-cataluna-20I804I20I5I_noticia. html> (consulta: març 2020).

- «Los CDR boicotean una manifestación en favor del castellano en Cataluña» (I6-09-20I8). A <https://www.abc.es/espana/catalunya/abci-manifestacionbarcelona-castellano-cdr-201809161623_noticia.html?ref=https:\%2F\%2Fwww. google.com $\% 2 \mathrm{~F}>$ (consulta: febrer 2020).

- «El constante desprecio al castellano en los programas de TV3» (30-IO-2018). A <https://www.abc.es/play/television/noticias/abci-constante-despreciocastellano-programas-201810291338_noticia.html> (consulta: febrer 2020).

- «Profesora, ¿puedo llorar en castellano?» (I9-II-20I8). A <https://www.abc.es/ sociedad/abci-profesora-puedo-llorar-castellano-20181II90202_noticia.html> (consulta: febrer 2020).

- «Los radicales organizan comandos para asaltar Barcelona» (I4-I2-20I8). A <https:// www.abc.es/archivo/periodicos/abc-madrid-20I8I2I4.html> (consulta: febrer 2020).

- «Sistemática erradicación del castellano» (9-03-2019). A <https://www.abc.es/ opinion/abci-sistematica-erradicacion-castellano-201903090004_noticia.html> (consulta: febrer 2020).

- «Omitir y sancionar el castellano» (I2-03-2019). A <https://www.abc.es/espana/ catalunya/abci-omitir-y-sancionar-castellano-201612282039_noticia.html> (consulta: febrer 2020).

- «La nueva consellera de Cultura de Quim Torra también firmó el manifiesto Koiné contra el castellano» (22-03-2019). A <https://www.abc.es/espana/catalunya/ politica/abci-nueva-consellera-cultura-quim-torra-tambien-firmo-manifiestokoine-contra-castellano-201903221407_noticia.html> (consulta: febrer 2020). 
- «La lengua de todos, arrinconada en Cataluña» (23-05-2019). A <https://www.abc. es/opinion/abci-lengua-todos-arrinconada-cataluna-201905230008_noticia.html> (consulta: febrer 2020).

- "¿A qué nos enfrentamos?»(30-09-2019). A <https://www.abc.es/opinion/abcienfrentamos-2019093000I7_noticia.html> (consulta: febrer 2020).

- «Mordaza a la lengua oficial» (24-II-20I9). A <https://www.abc.es/opinion/abcimordaza-lengua-oficial-2019II240IO2_noticia.html> (consulta: febrer 2020).

- «En Cataluña nueve de cada diez inspectores son nacionalistas o guardan silencio» (I7-I2-2019). A <https://www.abc.es/sociedad/abci-jesus-cataluna-nueve-cadadiez-inspectores-nacionalistas-o-guardan-silencio-2019I2I623II_noticia.html> (consulta: febrer 2020).

Ara

- «El català, en fora de joc» (4-OI-20I6). A <https://www.ara.cat/societat/catala-forajoc_O_I498050224.html> (consulta: febrer 2020).

- «El que més odien és la llengua» (I5-II-20I7). A <https://www.ara.cat/opinio/ sebastia-alzamora-mes-odien-llengua_O_1906609342.html> (consulta: febrer 2020).

- «La llengua de la causa general contra el dret a l'autodeterminació» (9-OI-20I9). A <https://www.ara.cat/opinio/josep-cruanyes_O_2158584332.html> (consulta: febrer 2020).

- «El català no mor, el matem» (27-OI-20I9). A <https://www.ara.cat/opinio/catalano-mor-matem_O_2169982994.html> (consulta: febrer 2020).

- «El català i l'estatus de llengua antipàtica» (I4-07-20I9). A <https://www.ara.cat/ opinio/catala-estatus-llengua-antipatica_O_2270772922.html> (consulta: febrer 2020).

- «El judici i la llengua dels aborígens» (I4-09-20I9). A <https://www.ara.cat/opinio/ sebastia-alzamora-judici-llengua-aborigens_O_2I80I82197.html> (consulta: febrer 2020).

\section{El País}

- «Patrias y fronteras» (27-09-20I5). A <https://elpais.com/politica/2015/09/25/ actualidad/I443182466_606909.html>

- «Contra los catalanes: El manifiesto monolingüista amenaza la convivencia y la inmersión escolar»(6-04-2016). A <https://elpais.com/elpais/2016/04/o5/ opinion/I459876988_969793.html> (consulta: febrer 2020). 
Rosa Calafat Vila

La ideologia en el discurs de la història de la llengua: el tractament del procés sobiranista

- «Luchas koinistas» (I3-04-2016). A <https://elpais.com/ccaa/20I6/o4/II/ catalunya/I460380099_090838.html> (consulta: març 2020).

- «Diccionario de la seducción independentista»(22-II-20I7). A <https://elpais.com/ politica/20I7/II/2I/actualidad/I5II269937_784275.html> (consulta: febrer 2020).

- «Un pacto por las lenguas»(26-02-20I8). A <https://elpais.com/politica/20I8/o2/26/ aixo_va_de_democracia_blog_contra_lio/I519636767_I5949o.html> (consulta: febrer 2020).

- «El falso diccionario del independentismo catalán» (26-03-2018). A <https://elpais. com/elpais/2018/03/25/hechos/I522010567_491793.html> (consulta: febrer 2020).

- «La tercera Cataluña»(8-04-2018). A <https://elpais.com/ccaa/2018/04/o7/ catalunya/I523126568_021755.html> (consulta: febrer 2020).

- «Paisaje catalán con rebelión al fondo»(29-IO-20I8). A <https://elpais.com/ politica/20I8/Io/26/actualidad/I540549776_939629.html> (consulta: febrer 2020).

- «República sin fraternidad»(19-03-2019).A <https:/elpais.com/elpais/2019/03/19/ opinion/1553013558_65447I.html> (consulta: febrer 2020).

- «El lazo amarillo entra en los libros»(22-06-2019). A <https://elpais.com/ cultura/2019/o6/22/actualidad/I56I218102_271968.html> (consulta: febrer 2020).

- «Conversaciones políticas con mi tostadora» (7-07-2019). A <https://elpais.com/ ccaa/2019/07/o7/catalunya/I562503876_458468.html>

- «Daños del 'procés' a Cataluña»(I-IO-2019). A <https://elpais.com/ccaa/20I9/ıo/oI/ catalunya/I569947385_192084.html> (consulta: febrer 2020).

- «La lengua como víctima en Cataluña» (28-IO-2019). A <https://elpais.com/elpais/2019/Io/24/ideas/I571938634_199278.html> (consulta: febrer 2020).

- «El método nacionalista» (27-II-2OI9). A <https://elpais.com/elpais/2OI5/II/2I/ opinion/I448130608_946512.html> (consulta: febrer 2020).

\section{El Punt Avui}

- «Qüestió de llengua»(30-07-20I6). A<https://www.elpuntavui.cat/opinio/article/8articles/991672-queestio-de-llengua.html> (consulta: febrer 2020).

- «El català $(\mathrm{NO})$ és la llengua pròpia de Catalunya» (3-08-20I7). A <https://www. elpuntavui.cat/politica/article/ı7-politica/II89573-el-catala-no-es-la-llenguapropia-de-catalunya.html> (consulta: febrer 2020).

- «Catalunya (NO) ha estat discriminada per la llengua» (5-08-20I7). A <https:// www.elpuntavui.cat/politica/article/II89577-catalunya-no-ha-estat-discriminadaper-la-llengua.html> (consulta: febrer 2020). 
- «Un programa de ràdio per als presos polítics» (25-I2-2017). A <https://www. elpuntavui.cat/politica/article/ı7-politica/I71628I-un-programa-de-radio-per-alspresos-politics.html> (consulta: març 2020).

- «No ens dividiran!»(16-02-2018). A <http://www.elpuntavui.cat/politica/article/I7politica/134219I-no-ens-dividiran.html> (consulta: febrer 2020).

- «Catalunya fa nosa» (13-07-2018). A <https://www.elpuntavui.cat/opinio/article/8articles/I430244-catalunya-fa-nosa.html $>$ (consulta: febrer 2020).

- «El procés no és per a cansats ni per a impacients» (I7-04-2019). A <https:// www.elpuntavui.cat/politica/article/I7-politica/1590138-el-proces-no-es-ni-pera-cansats-ni-per-a-impacients.html> (consulta: març 2020).

- «Un idioma en retirada (I i II)» (23-07-2019/30-07-2019). A <https://www.elpuntavui.cat/opinio/article/8-articles/I632860-un-idioma-en-retirada-I.html $><$ http:// www.elpuntavui.cat/opinio/article/8-articles/r633238-un-idioma-en-retirada-i-2. html> (consulta: febrer 2020).

- «La llengua prescindible» (9-09-2019). A <https://www.elpuntavui.cat/opinio/ article/8-articles/I6I662I-la-llengua-prescindible.html> (consulta: març 2020).

- «La discriminació del català, al jutjat» (19-09-2019). A <https://www.elpuntavui. cat/societat/article/5-societat/I638713-la-discriminacio-del-catala-al-jutjat.html> (consulta: febrer 2020).

\section{Vilaweb}

- «La nostra llengua està en perill de mort» (7-02-2016). A <https://www.vilaweb. cat/noticies/isabel-clara-simo-fer-se-gran-es-una-merda> (consulta: febrer 2020).

- «Enquestes lingüístiques i realitats cruels» (20-03-2016). A <https://www.vilaweb. cat/noticies/enquestes-linguistiques-i-realitats-cruels> (consulta: març 2020).

- «Denuncien que un professor s'enfronta a 600 euros de multa per parlar en català a dos policies a l'aeroport del Prat» (23-03-2017). A <https://www.vilaweb.cat/ noticies/denuncien-que-un-professor-senfronta-a-6oo-euros-de-multa-per-parlaren-catala-a-dos-policies-a-laeroport-del-prat> (consulta: febrer 2020).

- «La cultura en català només ens téa nosaltres» (4-04-20I7). A <https://www.vilaweb. $\mathrm{cat} /$ noticies/la-cultura-en-catala-nomes-ens-te-a-nosaltres $>$ (consulta: febrer 2020).

- «En el tercer aniversari (i tres mesos) del manifest Koiné» (04-04-20I7). A <https:// www.vilaweb.cat/noticies/manifest-koine-opinio-joan-ramon-resina> (consulta: febrer 2020). 
- «L'Any Pompeu Fabra arrenca amb una crida a enfortir la llengua catalana» (2I-02-20I8). A <https://www.vilaweb.cat/noticies/lany-pompeu-fabra-arrencaamb-una-crida-a-enfortir-la-llengua-catalana> (consulta: febrer 2020).

- «Anem cap a una 'irlandització' del català» (7-03-20I8). A <https://www.vilaweb. cat/noticies/quim-monzo-premi-dhonor-anem-cap-a-una-irlanditzacio-del-catala $>$ (consulta: febrer 2020).

- «Tu dius patata, jo dic Kartoffel»(9-04-20I8). A <https://www.vilaweb.cat/ noticies/tu-dius-patata-jo-dic-kartoffel-mail-obert-article-marta-rojals $>$ (consulta: març 2020).

- «El català ha perdut 300.00o parlants habituals a Catalunya en deu anys» (8-06-20I8). A <https://www.vilaweb.cat/noticies/el-catala-perd-300-ooo-parlants-habituals-acatalunya-entre-2003-i-20I3-segons-linformacat> (consulta: febrer 2020).

- «Si un sol espectador ho demana» (8-04-2019). A<https://www.vilaweb.cat/noticies/ politics-llengua-opinio-marta-rojals $>$ (consulta: febrer 2020).

- "Quan només dir 'bon dia' et costa dos-cents mil euros» (30-07-2019). A <https:// www.vilaweb.cat/noticies/discriminacio-linguistica-editorial-vicent-partal> (consulta: febrer 2020).

- «El llaç groc torna a la façana del Parlament de les Illes Balears» (II-09-20I9). A <https://www.vilaweb.cat/noticies/el-llac-groc-torna-a-la-facana-del-parlamentde-les-illes-balears> (consulta: març 2020). 